\title{
EL SALMO 137 (136), DE MAX AUB A JOSÉ SARAMAGO
}

\author{
Pasqual Mas Usó \\ Universitat Jaume I \\ pasqualmas@yahoo.es
}

\section{RESUMEN}

Tras un breve seguimiento del origen del Libro de los Salmos, el artículo se centra en el "Salmo 137 (136)" y en sus diversas versiones, desde la clásica de San Juan de la Cruz y la recreación de Luis de Camõens, a las modernas de T. S. Elliot, Stephen Vincent Benét, Thomas Merton, Ernesto Cardenal y Juan Gelman, con especial interés en los textos de Max Aub y José Saramago.

Palabras Clave: Max Aub, José Saramago, Biblia, poesía, salmo, exilio.

\section{Abstract}

After some short notes about the origin of The Psalms, this article is based on the classical recreations from The "Psalm 137 (136)", like poems from San Juan de la Cruz or Luis de Camõens, and on modern versions like the texts from T. S. Elliot, Stephen Vincent Benét, Thomas Merton, Ernesto Cardenal and Juan Gelman; with especial attention in Max Aub's and José Saramago's poems.

Keywords: Max Aub, José Saramago, Bible, Poetry, Psalm, Exile.

El Libro de los salmos es denominado en el texto hebreo sefer tehillin, y de ahí que pueda traducirse como Libro de Alabanzas o Libro de Himnos. El vocablo hebreo tehillin deriva de la raíz hll que significa himnos y por ello cabe la interpretación "alabanzas" o "cantos de alabanza". Es decir, que, como señala Jacir de Freitas Faria, en el nombre del libro ya está presente su propósito; esto es, el de alabar a Dios ${ }^{1}$. El texto hebreo de los Salmos es el más

${ }^{1}$ Freitas Faria, Jacir de (2005): "El Libro de los Salmos en su contexto literario", Ribla, 52 (San José de Costa Rica), pp. 1-16. 
antiguo y, aunque muy corrompido, es reconocido por la crítica como el mejor texto y de él parten las actuales traducciones. En cambio, el texto griego de los Salmos, también conocido como "Traducción de los Setenta", lleva por título Psalterium —como el instrumento musical de ocho cuerdas - por tratarse de la traducción del sustantivo hebreo mizmor, canto sagrado acompañado de un salterio.

Teodorico Ballarini y Venanzio Reale dividen litúrgicamente El Libro de los Salmos -a imitación del Pentateuco - en cinco colecciones: Yavista, atribuida a David (1-41); Eloísta, de origen judaico de comienzos del exilio babilónico (42-72); Eloísta, atribuida a Asaf, fundador de la escuela de cantores de los "Hijos de Asaf" (73-89), excepto 84-89 que son yavistas; Yavista (90-106), que no pudieron entrar en colecciones anteriores; y una última colección Yavista (107-50) en la que el nombre Yavé se repite numerosas veces². El texto elegido por Max Aub, José Saramago y los otros autores que aquí se estudiarán si bien tangencialmente, pertenece, por tanto, a la tradición yavista, destinada a agradecer a Dios su intervención salvadora.

El "Salmo 137", atribuido por algunos autores como James L. Kugel ${ }^{3}$ a Jeremías, es un texto intenso y enérgico que expresa los deseos de los judíos en el exilio tras la conquista babilónica de Jerusalén en el año 586 a.C. El salmo refleja tanto el amor al pueblo de Israel como el odio a los invasores.

En la clasificación del biblista Herman Hunkel4, el "Salmo 137" pertenece al grupo de los himnos (diferente del de súplicas, acción de gracias y géneros menores). Otros autores, como Erhard Gerstenberger ${ }^{5}$, optan por divisiones diferentes y, entre ellos, cabe destacar la clasificación de Marc Girard ${ }^{6}$ quién, basándose en que "el pueblo tiene cuatro necesidades fundamentales para satisfacer -librarse de los problemas, dejarse instruir, maravillarse con lo que es bello y hacer la fiesta"-, elabora cuatro familias: liberación, instrucción, alabanza y celebración de la vida. He aquí el tendencioso y resentido texto bíblico que tomarán Max Aub para componer su "Salmo CXXXVII" y Saramago su "Salmo 136":

\section{SALMO 137 (136)}

1 Junto a los ríos de Babilonia, nos sentábamos a llorar, acordándonos de Sión.

2 En los sauces de las orillas teníamos colgadas nuestras cítaras.

3 Allí nuestros carceleros nos pedían cantos,

2 Ballarini, Teodorico y Reali, Venanzio (1985): A poética hebraica e os Salmos, Petrópolis, Editora Vozes, pp. 41-42.

${ }^{3}$ Kugel, James L. (1994): "Salmo 137” adentro en la casa de Putifar. Cambridge, Prensa de la Universidad de Harvard.

${ }^{4}$ Hunkel, Hermann (1968a): Einleitund in die Psalmen, Gotinga, Vandenhoeck \& Ruprecht, 2a ed., y (1968b): Die Psalmen, Gotinga, Vandenhoeck \& Ruprecht, $5^{\text {a }}$ ed.

${ }^{5}$ Gerstenberger, Erhard (1982): Salmos, São Leopoldo, Faculdade de Teologia.

${ }^{6}$ Girard, Marc (1982): Como ler o livro dos Salmos - Espelho da vida do povo, São Paulo, Edições Paulinas, p. 19. 
y nuestros opresores, alegría:

"¡Canten para nosotros un canto de Sión!”

4 ¿Cómo podíamos cantar un canto del Señor

en tierra extranjera?

5 Si me olvidara de ti, Jerusalén, que se paralice mi mano derecha;

6 que la lengua se me pegue al paladar

si no me acordara de ti,

si no pusiera a Jerusalén

por encima de todas mis alegrías.

7 Recuerda, Señor, contra los edomitas,

el día de Jerusalén,

cuando ellos decían: “¡Arrásenla!

¡Arrasen hasta sus cimientos!”

8 ¡Ciudad de Babilonia, la devastadora,

feliz el que te devuelva el mal que nos hiciste!

9 ¡Feliz el que tome a tus hijos

y los estrelle contra las rocas!

Como se observará, mientras Max Aub elige la numeración de la Biblia Hebrea -número sin paréntesis- José Saramago opta por la de los libros litúrgicos, aunque se trata del mismo texto tomado como referencia.

La expansión del Cristianismo conllevó la necesidad de una nueva lectura de algunos textos bíblicos para que estos sirvieran al emergente poder de Occidente. San Juan de la Cruz fue uno de los que versionaron el "Psalm 136" — nuestro 137_ "David Hieremiae super flumina Babylonis illic sedimus et flevimus cum recordaremur Sion" al trasladar los versículos latinos al castellano en estructura de romance:

Encima de las corrientes

que en Babilonia hallaba,

allí me senté llorando,

allí la tierra regaba

acordándome de ti,

¡oh Sión!, a quien amaba. [...]

¡Oh, hija de Babilonia,

mísera y desventurada! $[\ldots]^{7}$

${ }^{7}$ Cruz, Juan de la (1982): Obra poética. Estudio crítico de Miguel de Santiago. Apéndice de Juan Pablo II. Barcelona, Río Nuevo, pp. 167-68. 
Pero el presente artículo se centra en la era moderna y de ahí el salto a principios del pasado siglo.

En 1922, Thomas Stearns Elliot (1888-1965), en la tercera estancia de The Waste Land ('La tierra baldía'), titulada "The Fire Sermon" ('El sermón del fuego'), retoma el "Salmo 137" cuando se echa a llorar a orillas del Leman: "By the waters of Leman I sat down and wept..." En la misma estancia, el personaje Tiresias representa al pasado, al presente y al futuro: al hombre contemporáneo capaz de ver lo que será a partir de lo que fue. Y el resto de personajes, como comenta Olga Osorio ${ }^{8}$, salidos del pasado y proyectados hacia la catástrofe, serán exiliados que regresan a sus hogares decadentes (el marinero y el pescador de caña), equiparados a Acteón (Sweeney), presentados como violadores (Tereo) o tenidos por aprovechados (soldado Albert). T. S. Elliot, que también introduce a los Apóstoles en la estancia quinta, aprovecha las referencias religiosas para construir un mural que alerta, a partir del texto bíblico, de la nadería a la que apunta la existencia humana.

También Stephen Vincent Benét (1898-1943), comenta Charles A. Fenton ${ }^{9}$ (1978), en su corta historia Por las aguas de Babylon (1937) elige el "Salmo 137" como referencia para situarse en un futuro, contado por el hijo de un sacerdote, previo al Great Burning en el que llovería fuego desde el cielo. Aparte de la coincidencia -señalada por Brainerd Duffield $^{10}$ - de adelantarse por muy pocos años a las bombas atómicas lanzadas sobre Japón, esta fantasía de Benét acaba de modo justiciero, pues el héroe, tras el fuego, se instala en un nuevo edén llamado New York Hotel Billmor. De hecho, la historia fue escrita en 1937 como respuesta al bombardeo de Guernica durante la Guerra Civil Española; y no se trata del único caso en el que Benét vuelca su mirada hacia España, pues en 1926 ya había escrito Spanish bayonét.

Al contrario que en "Salmo 135" y "Salmo 136" de Max Aub -todavía inéditos",desechados en las sucesivas ediciones del Diario de Djelfa", en los que Max Aub (19021972) prácticamente traduce los textos bíblicos, en el "Salmo CXXXVII" se distancia de las palabras originales, pero no del sentimiento de exilio, de prisión y de arrancado de una tierra amada que, a pesar de nacido en Francia y de ser de origen alemán, siente como suya. De hecho, en el momento de escribir el poema, en abril de 1942, Max Aub está prisionero en el desierto argelino, en Djelfa, un mes antes de dirigirse a Casablanca de camino a su exilio definitivo en México. He aquí el texto con el que Aub recupera las palabras de la Biblia para acerarlas y envenenarlas desde su exilio africano:

\footnotetext{
8 Osorio, Olga (2002): “La Tierra Baldía: un Palimpsesto del siglo xx”. Espéculo, Universidad Complutense de Madrid, no 20: http://www.ucm.es/info/especulo/numero20/eliot.html

${ }^{9}$ Fenton, Charles A. (1958): Stephen Vincent Benet: The Life and Times of an American Man of Letters, 18981943. Westport, Conn., Greenwood Press.

${ }^{10}$ Duffield, Brainerd (1971): Stephen Vincent Benet's By the waters of Babylon; a play in one act. Chicago: Dramatic Pub. Co., 1978.

11 Pueden solicitarse consulta en la Fundación Max Aub de Segorbe: (http://www.maxaub.org/) de Pasqual Mas i Usó, Catálogo del corpus poético inédito de Max Aub, 2010.

${ }^{12}$ Aub, Max (1944): Diario de Djelfa. México, Unión Distribuidora de Ediciones.
} 


\section{SALMO CXXXVII}

Junto a los ríos del desierto oscuro,

ríos de verdad y de sed

lloramos a España muerta,

la que fue.

“¡Si me olvidara de ti, ¡oh España!, mi diestra sea olvidada!".

¡Viento, si muero

lleva mi polvo

más allá del Estrecho!

Todo lo que canto

todo lo que canta,

desierto esclavo,

se llama España.

Lo perdido,

más vivo.

¡Extranjeros, vosotros

que dormís en nuestras camas!

¡Españoles nosotros,

polvo y tierra de España,

extranjeros

en las arenas del Sahara!

Junto a los ríos del desierto oscuro

no lloramos, no.

¡Llorar es de tontos,

aguantamos, España, aguantamos

y te esperamos!

¡Ay, extranjeros que dormís en camas,

en la España nuestra!

¡Cada grano de arena

clavo ardiendo se os vuelva!

(¡Madrid! ¡Castilla!

¡Cádiz! ¡Valencia!)

¡Cada terrón 
piedra se os vuelva!

¡Que cada miembro

se os vuelva tierra,

orillas del Guadiana,

orillas del Esgueva!

Vigo, Coruña

y Cartagena:

¡dadles mil muertes

por nuestras penas!

Junto a los ríos del desierto oscuro,

España nuestra, arena

entre cielo y cielo.

España río,

recuerdo y sueño.

¡Ay viento, si yo muero

lleva mi polvo

más allá del Estrecho!

¡Bilbao, Lécera

idles cambiando

pelo en culebras!

¡Ay viento, si yo muero

lleva mi polvo

más allá del Estrecho!

$4-4-42^{13}$

Max Aub, desde su exilio en Djelfa, se decide por conservar el espíritu de quien anhela su tierra perdida, arrebatada, y expresa el deseo de recuperarla. No son pocos los poemas en los que Aub repite este sentimiento, incluso en boca de heterónimos como exiliados sefardíes. También está presente aquí, como en el texto bíblico, el deseo de revancha contra el ocupador de la tierra.

Dos días antes Max Aub había escrito "Simún”, donde también aparece ese "Polvo, tormenta y tormento (...) la arena de duna en duna. Tierra que aterra y aterra / en el cielo

13 Aub, Max (2001): Obra Poética Completa, I. Introducción de Arcadio López Casanova; edición y notas de López Casanova, Arcadio; Mas i Usó, Pasqual; Calles, Juan María; et alteri. Valencia, Biblioteca Valenciana, 2001, 148-49. 
vuelto y revuelto"14. Y, el mismo día que el "Salmo CXXXVII", Aub escribe el poema "Día gris y noche despejada”, que cierra con "¡Noche y día igualada / muerta concha cerrada!"15. Será unos días después, el 8 de abril, cuando en "Plegaria a España" —subtitulada "Según los salmos $L X X I X$ y $L X X X$ ”-, Max Aub insista en la desgracia que sufre su país:

¡Oh, España mía, violada cada mañana!

¡Oh, España nuestra, cementerio abierto!

¿Por qué nos desamparas?

Aquí estamos por ti y tenemos que soportar

las risas y las burlas

Que despiertan tu amor.

Somos afrentados porque creemos en ti.

¿Hasta cuándo, España? ${ }^{16}$

Y continúa en el mismo poema con la revancha del "Salmo CXXXVII”: ¡Derrama tu ira sobre los que no te aman, / No dejes rastro de ellos"17. Pero será al final de este poema cuando llame a su país para que venga a salvarlo de la cárcel y del exilio.

¿Hasta cuándo humearás tú contra la oración

de tu pueblo verdadero?

Tú que extendiste la vida hasta el mar y los mugrones

hasta más allá.

¿Para qué? ¿Para que se alimenten el puerco y la bestia?

¡Oh, España!

Vuélvete a nosotros y sálvanos, castiga a los culpables

con los brazos y los muñones de la vid.

Quemada a fuego estás, asolada, patria, tierra de todos, vieja España nuestra.

¡Clávales las lenguas! ¡Ábrete y traga a los traidores!

¡Haz que nuestros brazos puedan ayudarte! ${ }^{18}$

Las fuentes que brotan del texto bíblico, sin embargo, no paran de manar. Y así, el monje trapense Thomas Merton (1915-1968) presenta en "The captive. A psalm", poema publicado en 1949, dentro de The tears of the Blind Lions — el mismo año de su ordenación-, a un rey que gobierna en una ciudad corrompida que, como en "The City After Noon", es como una

\footnotetext{
${ }^{14}$ Aub, Max (2001): p. 146.

15 Aub, Max (2001): p. 147.

16 Aub, Max (2001): p. 150.

17 Aub, Max (2001): p. 151.

${ }_{18}$ Aub, Max (2001): p. 152.
} 
prisión que ensombrece el presente de sus habitantes y los proyecta, según Arianna Fabbri ${ }^{19}$, hacia un futuro más esperanzado. El poema de Merton, como se observa, no escatima imágenes traídas a la actualidad.

The Captives - A Psalm

Quomodo cantabimus canticum Domini in terra aliena?

Somewhere a king walks in his gallery

Owning the gorges of a fiery city.

Brass traffic shakes the walls. The windows shiver with the business.

It's the bull's day. The citizens

Build themselves each other another god

And fry a fatter idol out of mud.

They cut themselves a crooked idiom

To the winged animals, upon their houses.

Payers made of money, songs of numbers,

Hymns of the blood of the killed.

Old ladies are treasured in sugar

Young ones rot in wine.

The flash of the fat organizers smiles with oil.

Blest is the army that will one day crush you, city,

Like a golden spider.

Blest are they that hate you. Blest are they

That dash your brats again the stones.

The children of God have died, o Babylon,

Of thy wild algebra.

Days, days are the journey

From wall to wall. And miles

Miles of houses shelter terror.

And we lie chained to their dry roots, O Israel!

Our bodies are greyer than mud.

There, butterflies are born to be dancers

And fly in black and blue along the drunken river

Where, in the willow trees, Assyria lynched our song!

\footnotetext{
19 Fabbri, Arianna (2007): “Y son cosas que los que se aman se dicen en la cama” La poesia mistica di Ernesto Cardenal. Tesis Doctoral. Università di Bologna, p. 71.
} 
May my bones burn and ravens eat my flesh

If I forget thee, contemplation!

May language perish from my tongue

If I do not remember thee, O Sion, city of vision

Whose heights have windows finer than the firmament

When night pours down her canticles

And peace signs on thy watchtowers like the stars of Job ${ }^{20}$.

En un paralelismo neoplatónico próximo al de Luis de Camõens, "Merton —afirma Sonia Petisco $^{21}$ - lleva al límite la polaridad agustiniana entre la ciudad terrenal (la Babilonia de Louisville) donde "the windows shiver with business", y el Sión de Getsemaní, morada de contemplación y de visión, en la que vuelve a aparecer el símbolo recurrente de la poesía mertoniana de la ventana entendida como apertura a una realidad trascendente. A parte de la inocente profecía de que la Nueva Jerusalén, para Thomas Merton, se habrá de construir a orillas del río Ohio, puede rastrearse la dicotomía augustiniana de Merton en dramas como The Tower of Babel o en extensos poemas como "Christopher Columbus", en el que tras cruzar el Atlántico el héroe gigantesco se enfrenta al poder del dinero que gobierna las "sarcastic towns".

José Saramago no dejará pasar el salmo bíblico sin acentuarle la desolación del que se siente alejado de su tierra: Portugal. La poesía de José Saramago, por otra parte, es poco conocida si se toma la palabra en el sentido más corriente: como texto cuyo desarrollo se plasma exclusivamente en el poema. Sin embargo, poesía es Levantado del suelo, libro en prosa que narra la saga de campesinos del Alentejo. ¿O acaso no puede entenderse también La caverna como un tierno poema social? El perfil de Saramago no está completo, por tanto, si se ignora esta vertiente reflexiva y precisa que busca los límites del lenguaje.

José Saramago publicó sólo tres libros de poesía: Los poemas posibles (1966), Probablemente alegría (1970) y El año de 1993 (1975). Su "Salmo 136" está incluido dentro del apartado "Poema a boca cerrada" del primero de sus libros y es el acercamiento de un ateo convencido - como en El evangelio según Jesucristo- a un salmo bíblico, del que se distancia para interrogar a la sociedad sobre las desgracias que provoca. Más tarde, en los Cuadernos de Lanzarote fundamentará la no existencia de Dios en la existencia del hombre, un punto de vista que el "Salmo 136" del portugués también pondrá de relieve y, como revancha del destino cancelará el poema con un adagio sentencioso que encierra la revelación de un destino forjado por la impericia humana: se consigue lo que uno se labra. Saramago escribe al respecto el 2 de mayo de 1993: “CCómo será posible creer en un Dios creador del Universo, si el mismo Dios creó la especie humana? Con otras palabras, la existencia del hombre, precisamente, es lo que prueba la inexistencia de Dios"22.

${ }^{20}$ Merton, Thomas (1977): The Collected Poems of Thomas Merton, New York, New Directions, p. 212.

${ }^{21}$ Petisco, Sonia (2003): La poesía de Thomas Merton, poesía, crítica y contemplación. Memoria de doctorado, Universidad Complutense de Madrid, p. 26.

${ }^{22}$ Saramago, José (2011): Cuadernos de Lanzarote, I (1993-1995). Madrid Alfaguara. Traducción de Eduardo Naval, p. 49. 
Horácio $\operatorname{Costa}^{23}$ analiza en el análisis del período formativo del autor de Azinhaga el gusto por el verbo culto y entresaca un ejemplo de su "Salmo 136", donde retoma la redondilla "Sôbolos ríos" ( 'Sobre los ríos') de Luis de Camõens, publicada en 1595, y aprovecha para censurar la vida portuguesa afirmando que "Têm os povos as musicas que merecem" ('Tienen los pueblos las músicas que merecen'). Quizá por ser el "Salmo 136” de Saramago un poema de su primera época se corre el peligro de identificar su clasicismo, señalado por Horácio Costa, con la voz de Ricardo Reis, celebrado heterónimo de Pessoa, pero ni el tono ni el vocabulario llevan a esa conclusión.

Horácio Costa ofrece una pista que conduce a Camõens, pero, así mismo, el poema "Sôbolos Ríos" es un diálogo con la Historia Sagrada que lleva a San Agustín y al platonismo que descansa sobre los dualismos tierra y cielo o gracia y pecado. Camõens, peregrino en tierras de China y de África, "exiliado" en parte — como Saramago_-, recupera en su poema la nostalgia de su tierra y se apoya en la Biblia para ponerse del lado del que alaba a Israel, la Tierra Santa: es decir, la vida propia, terrena, instalada en el purgatorio, entra en diálogo con la celeste. Camõens escribe desde su exilio en África refiriéndose al sufrimiento del pueblo judío en tierras de Babilonia y teniendo como fondo la profecía de Jeremías sobre su destrucción. En efecto, en el libro de Jeremías se lee: "castigaré al rey de Babilonia y a aquella nación por su maldad, ha dicho Jehová, y a la tierra de los caldeos; y la convertiré en desiertos para siempre". (Jeremías, 25, 12)

De ahí que no cueste apreciar la similitud entre el verso de cierre del poema de Saramago y los siguientes de Camõens de "Sôbolos ríos":
A pena desse desterro,
que eu desejo esculpido
em pedra, ou em feno duro.
Essa nunca seja ouvida
Em castigo de meu erro. ${ }^{24}$

José Saramago toma como referencia el principio de "Sôbolos ríos" y actualiza la visión autodestructiva enlazando el pasado con el presente y presagiando un futuro ciertamente desolador. Dice Camõens:
"Sôbolos rios que vão
Por Babilônia m'achei,
Onde sentado chorei
As lembranças de Sião,
E quanto nela passei.

\footnotetext{
${ }^{23}$ Costa, Horacio (2004): José Saramago: el periodo formativo, México, FCE, p. 59.

${ }^{24}$ Camõens, Luis de (1860): Obras de Luiz de Camões: precedidas de um ensaio biographico, no qual se relatam alguns factos não conhecidos da sua vida, Por Luís de Camões, João Antonio de Lemos Pereira de Lacerda Juromenha, Francesco Petrarca, Publicado por Imprensa Nacional, vv. 186-190.
} 
Ali o rio corrente

De meus olhos foi manado;

E tudo bem comparado,

Babilônia ao mal presente

Sião ao tempo passado." 25

Y sentencia el texto de José Saramago:

SALMO 136

Ni por abandonadas se callaban

Las harpas de los sauces suspendidas.

Si los dedos de los hebreos no las tocaban,

En las cuerdas tensas el viento de Sión

La música de la memoria repetía.

Mas en la Babilonia en que vivimos,

Sión en el recuerdo y el futuro,

Hasta el viento calló la melodía.

Tanto nos dejamos arrasar,

Más que el cuerpo, el alma y el deseo,

Que ni sentimos ya el hierro duro,

Si nos dejaron la vanidad de lo que fuimos.

Tienen los pueblos las músicas que merecen. ${ }^{26}$

Como se observa, y se ha advertido más arriba, en realidad el salmo bíblico al que se refiere Camõens y Saramago es el 137 - antiguo 136- en el que los seis primeros versículos reflejan la nostalgia de Jerusalén y los tres últimos son una imprecación contra los enemigos de Israel.

Por otra parte, Saramago escapa de Camõens y del pensamiento agustiniano que trata de repetir en las personas las pautas atribuidas a Jesús: nacimiento, vivencias, muerte, resurrección y ascensión. En Saramago no hay pecado, hay responsabilidad. Camõens va sustituyendo la memoria por la reminiscencia, la confusión por la paz, la tristeza por la alegría y el amor profano por el amor puro para hacernos ver que la felicidad no puede encontrarse en una Babilonia tan humana, sino en una Jerusalén glorificada a la que no todos tendrán acceso. Saramago, en cambio, lejos de buscar la trascendencia con su mensaje, filtra el bíblico "Salmo 137" a través de Camõens pero lo despoja del platonismo para llevarlo a un derrotista terreno moral y cívico: tenemos lo que merecemos.

\footnotetext{
${ }^{25}$ Camõens (1860): vv. 1-10.

${ }^{26}$ Saramago, José (2011): Poesía Completa. Madrid Alfaguara. Traducción de Ángel Campos Pámpano, p. 72.
} 
Ernesto Cardenal (1925), poeta militante, también se decantó por el "Salmo 137” y es el más osado en cuanto a la actualización del lenguaje, pues, a tenor de los ejemplos aportados por Eduardo Urdavinia Bertarell27, convierte los símbolos de la depravación en "rascacielos", "night clubs" o "armada de bombas", y utiliza palabras con poderosa carga negativa, como "cáncer":

[... ]que se me seque la lengua

y tenga cáncer de boca

si yo no me acordara de ti Jerusalén!

Geneviève Fabri ${ }^{28}$ es quien mejor ha estudiado al autor nicaragüense, como también al argentino Juan Gelman (1930) que, en poemas como el "Comentario XIII (san Juan de la Cruz)", perteneciente al poemario Citas y comentarios, alude a los textos bíblicos a través del místico español.

La conexión entre Juan Gelman y San Juan de la Cruz, estudiada por Elisa Martín Ortega $^{29}$ y Diana García Simón ${ }^{30}$, se establece a partir del sentimiento de soledad, ausencia y, como consecuencia, de estar exiliado del lugar deseado ${ }^{31}$. En los 109 poemas recogidos por Juan Gelman en 1982 en Citas y Comentarios -escritos entre 1978 y 1979-, se establece un diálogo con la Mística Española y, más concretamente con Santa Teresa y San Juan de la Cruz. Gelman, buscando el paralelismo de los ríos babilónicos, vuelve a los salmos en otros poemarios, como Com / posiciones, pero es en "Comentario XXIII (san Juan de la Cruz)", interpretado místicamente por María del Carmen Sillato ${ }^{32}$, en donde más clara queda la voluntad de Juan Gelman de reivindicar su presencia en su país desde su exilio, y de ahí que dedique la totalidad del poemario "A mi país".

esta herida con vos /o llaga /luz

como criatura vulnerada o

pena de vos que vivemuere

hasta que la matás haciéndola ${ }^{33}$

27 Urdavinia Bertarelli, Eduardo (1984): La poesía de Ernesto Cardenal: cristianismo y revolución, Lima, Latinoamericana, p. 179.

${ }^{28}$ Fabri, Geneviève (2003): "Reescrituras del Salmo 136 (137). De Ernesto Cardenal a Juan Gelman pasando por San Juan de la Cruz", en Federico García Lorca et Cetera. Estudios sobre las literaturas hispánicas en honor de Christian de Paepe. Université Leuven, Université Press, pp. 457-68. Y (2005): "La estructura del duelo en la poesía de Juan Gelman", Anuario de Estudios Filológicos, XXVIII, pp. 55-69.

${ }^{29}$ Martín ortega, Elisa (2008-2009): “Juan Gelman y San Juan de la Cruz: migraciones poéticas”. Réécritures, III: http://www.crimic.paris-sorbonne.fr/actes/sal4/martin.pdf

${ }^{30}$ García Simón, Diana (1998): "Juan Gelman, una mística porteña”, en Claudius Armbruster/Karin Hopfe (Ed.): Horizontverschiebungen. Interkulturelles Verstehen und Heterogenität in der Romania. Tübingen, Gunter Narr Verlag.

31 Vid. al respecto el artículo de Ibáñez Quintana, Jaime (2004): "Poesía del exilio de Juan Gelman”, Espéculo, Universidad Complutense de Madrid: http://www.ucm.es/info/especulo/numero27/jgelman.html

32 Sillato, María del Carmen (1966): Juan Gelman: las estrategias de la otredad. Heteronimia, intertextualidad, traducción. Rosario, Beatriz Viterbo. Y (1988): “Dibaxu de Juan Gelman. La poesía desde las «exiliadas raíces» de la lengua", Actas del Congreso Asociación Internacional de Hispanistas, tomo III: http://cvc.cervantes.es/literatura/ aih/pdf/13/aih_13_3_056.pdf

${ }_{33}$ Gelman, Juan (1982): Citas y Comentarios. Madrid, Visor, p. 35. 
En sus poemas, esa sintaxis barrada que hace imposible la fluidez, es la que reverencia el paralelismo característico de los salmos y, más concretamente, del 137 en poemas "firmados" por el propio David. Véase, por ejemplo el "Comentario LVIII (rey David)":

$$
\begin{aligned}
& \text { Como animal sediento que } \\
& \text { busca las aguas/tierra mía } \\
& \text { te busco/o alma de volar } \\
& \text { para rodearte como vuelo }
\end{aligned}
$$

En resumen, el "Salmo 137 (136)", debido a su componente de llamada a la tierra de la que uno se encuentra ausente, ha servido a diversos poetas como fuente de inspiración para tratar el tema del exilio. El hecho de centrarse en Max Aub y José Saramago es por tratarse de excelentes autores cuya producción poética ha quedado siempre en segundo plano y porque sus respectivas versiones reflejan un componente humano poderosamente reivindicativo y comprometido. 
